\title{
Erratum to: Lithospheric structure of NW Iran from $P$ and $S$ receiver functions
}

\section{Fataneh Taghizadeh-Farahmand • \\ Forough Sodoudi • Narges Afsari • \\ Mohammad R. Ghassemi}

Published online: 3 September 2010

(C) Springer Science+Business Media B.V. 2010

\section{Erratum to: J Seismol}

DOI 10.1007/s10950-010-9199-2

Unfortunately, the image published for Fig. 6a was a duplicate of Fig. 5. In this erratum paper, the correct Fig. 6a is shown.
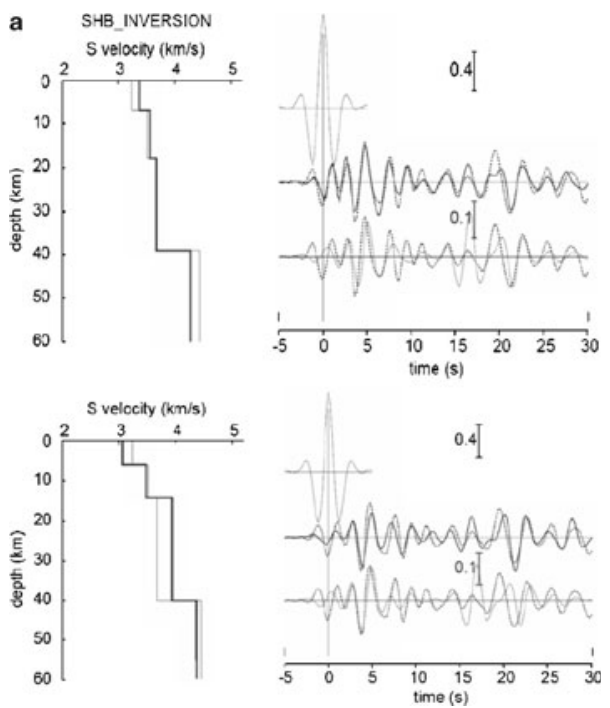

The online version of the original article can be found at http://dx.doi.org/10.1007/s10950-010-9199-2.

F. Taghizadeh-Farahmand $(\varangle)$

Department of Physics, Qom Branch,

Islamic Azad University, Qom, Iran

e-mail: f_farahmand@Qom-iau.ac.ir

F. Sodoudi

Helmholtz Center Potsdam,

GFZ Research Center for Geosciences,

Telegrafenberg 14473, Potsdam, Germany
N. Afsari

Department of Physics, Islamshahr Branch, Islamic Azad University, Tehran, Iran

M. R. Ghassemi

Research Institute for Earth Sciences,

Geological Survey of Iran, Azadi Sq., Meraj Ave.,

P.O.Box: 13185-1494, Tehran, Iran 